\title{
CRENÇAS SOBRE O ENSINO-APRENDIZAGEM DE LÍNGUAS: UM PANORAMA DAS DISSERTAÇÕES PRODUZIDAS NO BRASIL
}

\author{
NICLEIDE MARIA DO NASCIMENTO (UERN) ${ }^{1}$ \\ FRANCISCO ELIEUDO DE OLIVEIRA (UERN) ${ }^{2}$ \\ MARCOS NONATO DE OLIVEIRA (UERN) ${ }^{3}$
}

\begin{abstract}
RESUMO: O estudo das crenças sobre o ensino-aprendizagem de línguas tem despertado interesse de pesquisadores nos cursos de pós-graduação, especificamente no campo da Linguística Aplicada, por se tratar de um assunto que traz muitas implicações para a sala de aula. Este trabalho tem como objetivo investigar as pesquisas em crenças sobre o ensino-aprendizagem de línguas, apresentando um panorama das dissertações produzidas nos programas de pós-graduação no Brasil. Trata-se de uma pesquisa de natureza quali-quantitativa, descritiva e interpretativista. Para isso, apresentamos quantitativamente as dissertações produzidas nos cursos de pós-graduação no Brasil desde a década de 90, e analisamos, sob uma abordagem qualitativa, as dissertações produzidas no ano 2018, nos reportando aos seguintes aspectos: os objetivos pretendidos por essas pesquisas, a metodologia utilizada e os resultados alcançados. Adotamos como referencial teórico as contribuições de Barcelos (2001, 2004, 2007); Silva (2007); Bomfim; Conceição (2009); Santos (2009); entre outros. Enfatizamos a relevância dessas pesquisas para (re)construção de práticas pedagógicas e para melhoria do processo de ensino-aprendizagem de línguas. Os resultados mostram um crescente interesse pelas pesquisas em crenças e a importância dessa temática para as discussões, reflexões e para as ressignificações das práticas de ensino de línguas.
\end{abstract}

PALAVRAS-CHAVE: Crenças. Ensino-aprendizagem de línguas. Dissertações.

ABSTRACT: The study of beliefs about language teaching and learning has aroused the interest of researchers in postgraduate courses in the field of Applied Linguistics, that is so because it is a subject with a lot of implications for the classroom. This paper aims at investigating the research on beliefs about language teaching and learning, presenting an overview of the theses produced in postgraduate programs in Brazil. This is a quali-quantitative, descriptive and interpretative research. For this, we present quantitatively the theses produced in postgraduate courses in Brazil since the 90's, and analyze, under a qualitative approach, the theses produced in the year 2018, referring to the following aspects: the objectives intended by these researches, the methodology used and the results achieved. We emphasize the relevance of these researches for the reconstruction of pedagogical practices, and for improving the teaching-learning process of language teaching. The results show a growing interest in belief research and the importance of this theme for discussions, reflections and for the resignification of practices in the language-teaching.

KEYWORDS: Beliefs. Language teaching-learning. Theses.

\section{INTRODUÇÃO}

As crenças sobre o ensino-aprendizagem de línguas vêm sendo objeto de estudo de muitas das pesquisas desenvolvidas nos programas de pós-graduação no Brasil (LIMA, 2018; SANTOS, S., 2018; SANTOS, G., 2018). As primeiras discussões ganharam repercussão nos anos 1980, no exterior, junto com outros temas inerentes à Linguística Aplicada. No Brasil, os debates em torno desse tema surgiram a partir do início dos anos 1990. Mas foi somente após

\footnotetext{
${ }^{1}$ Mestranda em Ensino pela Universidade do Estado do Rio Grande do Norte, e-mail: nicleide.nascimento@gmail.com

${ }^{2}$ Mestrando em Ensino pela Universidade do Estado do Rio Grande do Norte, e-mail:ev elieudo@hotmail.com

${ }^{3}$ Professor Doutor, Universidade do Estado do Rio Grande do Norte, e-mail: marcosnonato@uern.br Revista Trama | Volume 16 | Número 37 | Ano 2020 | p. 71-83 | e-ISSN 1981-4674
} 


\section{$=$ TRAMA $=$}

os anos 2000 que se pode notar uma ampliação das discussões e pesquisas acerca das crenças nos processos de ensinar e aprender. Desde então, o tema tem sido interesse de muitos pesquisadores tanto do campo da Linguística Aplicada como de outras áreas das ciências humanas e sociais (BARCELOS, 2004, 2007; SILVA, 2007).

Levando em consideração o interesse e a relevância dessas pesquisas para a área de ensino e as muitas implicações que as crenças possuem para a sala de aula, objetivamos, neste trabalho, investigar as pesquisas em crenças sobre o ensino-aprendizagem de línguas. Por meio de um levantamento quantitativo, procuramos apresentar um panorama das dissertações produzidas nos programas de pós-graduação no Brasil a partir dos anos 1990 até 2018. Decidimos investigar somente dissertações devido ao grande número de trabalhos existentes. Selecionamos as dissertações de $2018^{4}$ para fazer uma análise qualitativa, apontando e discutindo os objetivos almejados, as questões metodológicas dessas pesquisas e os resultados alcançados. Procuramos ainda refletir sobre as implicações e as contribuições desses estudos para a ressignificação de práticas pedagógicas voltadas para o ensino de línguas.

Inicialmente, discutimos o conceito de crenças e suas características, buscando enfatizar sua relação com o processo ensino-aprendizagem; ainda apontamos suas implicações para a construção do saber, a partir de alguns trabalhos produzidos no Brasil. Em seguida, discorremos sobre os aspectos metodológicos desta pesquisa. $\mathrm{Na}$ análise de dados, apresentamos quantitativamente as dissertações produzidas nos cursos de pós-graduação no Brasil a partir dos anos 90, e analisamos as dissertações produzidas no ano 2018, observando os seguintes aspectos: a quantidade de trabalhos produzidos, os programas que mais produziram, os temas mais recorrentes nos estudos realizados, os objetivos pretendidos, a metodologia utilizada para o desenvolvimento das referidas pesquisas, bem como os resultados alcançados. Enfatizamos a relevância dessas pesquisas para (re)construção de práticas de ensino de línguas e para melhoria do processo de ensino-aprendizagem nas instituições educacionais de nosso país.

\section{CRENÇAS E SUA RELAÇÃO COM O ENSINO-APRENDIZAGEM DE LÍNGUAS}

Quando pensamos nas crenças sem fazermos referência ao processo ensinoaprendizagem, logo as relacionamos a ideias, opiniões e convicções que temos acerca de nossa vida e de tudo que nos rodeia, repercutindo em nossa postura diante de nós mesmos, dos outros e em relação ao ambiente do qual fazemos parte. Assim, podemos dizer que as crenças fazem parte da construção do nosso ser, implicando em nossas decisões, ações e emoções. Partindo dessa ideia preconcebida, parece fácil definir crenças. Mas será mesmo que essas noções são suficientes para defini-las? O que realmente são crenças? O que elas têm a ver com o processo de ensinar-aprender? Que importância apresentam para a área de ensino? Que implicações têm para a construção do conhecimento? A partir desses questionamentos, pretendemos inicialmente discutir o conceito de crenças e suas características, sua relação com o processo ensino-aprendizagem, bem como as implicações que esse tema da Linguística Aplicada (doravante LA) possui para a área de ensino de línguas.

Cada vez mais, pesquisadores em LA têm se interessado pela investigação das crenças no processo de ensino-aprendizagem (BARCELOS, 2004; SILVA, 2007), buscando entender sua relevância e implicações para o processo de ensino não só relacionadas à linguagem, mas também em outras dimensões do saber. Apesar de termos um recorte histórico de quando se firmou o desencadeamento dessas discussões, "o conceito de crenças é tão antigo quanto

\footnotetext{
${ }^{4}$ Escolhemos não contemplar as dissertações produzidas em 2019 em função de ser um ano ainda em andamento no período de realização da pesquisa.

Revista Trama | Volume 16 | Número 37 | Ano 2020 | p. 71-83 | e-ISSN 1981-4674
} 


\section{$=$ TRAMA $=$}

nossa existência, pois desde quando o homem começou a pensar, ele passou a acreditar em algo" (BARCELOS, 2007, p. 113). Todavia, pesquisas realizadas sobre esse tema, no contexto da LA, apontam para a necessidade não só de refletir sobre seu conceito, mas também de entender as implicações que possuem para o contexto da sala de aula (BARCELOS, 2007; SANTOS, 2009).

De acordo com Barcelos (2004), as discussões sobre crenças tiveram início a partir de mudanças de paradigmas dentro da $L A$, sobre perspectivas de ensino relacionadas à linguagem e sobre a visão que se tinha de aluno. Nessa conjuntura, o aprendiz passou a ocupar um lugar de destaque no processo ensino-aprendizagem, deixando de ser mero reprodutor de informações para ocupar um papel ativo dentro do processo. Nos anos 50, os aprendizes de língua imitavam o comportamento linguístico do professor, sendo meros reprodutores. Nos anos 60 , eram vistos como sujeitos capazes de descobrir as regras da língua. Nos anos 70 , passaram a ser enxergados como sujeitos afetivos e sociais; nos anos 1980, com capacidade autônoma de resolver problemas, e nos anos 90, como possuidores de uma dimensão política.

Embora muitas pesquisas sobre crenças na área de ensino já tenham sido realizadas, não há um consenso em relação a definição de seu conceito. Por muito tempo, acreditou-se que seu conceito estava relacionado ao conhecimento metacognitivo, sendo originado de experiências individuais de cada aprendiz e compreendido como a forma que cada um acredita que aconteça o processo cognitivo. As crenças eram tidas como conhecimento estável, fixo, abstrato, restrito a mente do aprendiz, podendo ser consideradas certas ou erradas (AVILA; MARCHESAN, 2017). Com o avanço das pesquisas sobre esse tema da LA, houve um entendimento para além do conceito cognitivo. Atualmente, as crenças são concebidas como mecanismos formados muito cedo e são resultantes de experiências e da interação entre os sujeitos. Apresentam-se como uma "[...] forma de pensamento, construções da realidade, maneiras de ver e perceber o mundo" (BARCELOS, 2004). Assim, há um entendimento de que a construção das crenças se dá pela influência do contexto, pela interação social e pela relação que o sujeito estabelece com o meio onde está inserido. Elas se materializam através de hábitos, costumes, tradições, maneiras de pensar e agir.

Bonfim e Conceição (2009) apresentam algumas definições, bem como alguns pressupostos básicos em relação às crenças, a saber: a) ideias ou noções preconcebidas sobre aspectos de aquisição de segunda língua; b) opiniões baseadas em experiências e opiniões de outras pessoas respeitadas, capazes de influenciar o agir das pessoas; as crenças podem ser compreendidas como conhecimento metacognitivo, ou seja, conhecimento estável, falível de um aprendiz sobre o processo cognitivo; c) crenças podem ser também resultado de aprendizagens adquiridas e/ou construídas de maneira formal e informal e que influencia ou até determina futuras aprendizagens. Ainda podem ser definidas como processos interativos que se constroem a partir das interações sociais e que podem influenciar ou não aprendizagens de línguas.

Os muitos termos e as muitas definições sobre crenças nos levam a perceber que elas, em diferentes momentos de sua investigação, estiveram relacionadas a: opiniões, experiências, expectativas, ideias, intuição, concepções que os aprendizes tinham em relação à aprendizagem. Portanto, as crenças "[...] podem ser definidas como opiniões e ideias que alunos (e professores) têm a respeito dos processos de ensino e aprendizagem de línguas" (BARCELOS, 2001, p. 72). Crenças podem ainda ser definidas como construções, resultantes de nossas experiências e interação com o contexto, de nossa capacidade de refletir sobre o que nos rodeia. Desse modo, são resultados de experiências cognitivas, culturais e sociais. 


\section{$=$ TRAMA $=$}

As crenças apresentam uma variedade de características que podem ser fundamentais para o entendimento de seu conceito. Sobre esse assunto, Barcelos (2007) afirma que há uma nova visão sobre as crenças e estas são caracterizadas pelo menos de oito formas. A primeira característica implica conceber as crenças como dinâmicas, ou seja, elas não são estanques, ao contrário, mudam-se de um período para outro, a depender do tempo ou até mesmo da situação vivenciada pelo sujeito. A segunda característica corresponde ao fato delas serem vistas como emergentes, isto é, não surgem do nada, são consequências de algo, nascem a partir das interações e das relações com os grupos sociais. Uma outra característica diz respeito ao fato delas serem socialmente construídas e situadas contextualmente, o que significa dizer que não são estruturas mentais prontas e fixas, ao contrário, mudam, transformam-se e desenvolvem-se a partir das interações sociais e das experiências adquiridas através dessas interações. Por desenvolverem-se a partir das interações sociais e das relações com o meio, as crenças são experienciais, são também mediadas, ou seja, podem direcionar as ações dos sujeitos, podem ser usadas para regular a aprendizagem e servir de guia para a superação de problemas. Também são paradoxais e contraditórias, isto é, são sociais, mas também individuais. As crenças também estão relacionadas à ação de uma maneira indireta e complexa, o que implica dizer que elas podem tanto influenciar o comportamento dos sujeitos ou estes podem agir de forma contraditória às suas crenças. Além disso, podem ser concebidas ainda como elemento não tão facilmente distinta do conhecimento, por vezes, confundidas com aspectos, tais como: conhecimento, motivação e estratégias de aprendizagem.

Além dessas características, as crenças apresentam algumas implicações para a área do ensino. Barcelos (2004) aponta três delas: 1) relação entre crenças e ações, ou seja, crenças influenciam ações, embora esta não seja uma noção precisa, pois conforme já mencionamos, as crenças são dinâmicas, sociais, contextuais e, por assim serem, é possível que alguma atitude de um professor, por exemplo, pode não corresponder ao que ele acredita, ou seja, é possível que as ações não correspondam às crenças. 2) Necessidade de criar oportunidades em sala de aula para que alunos possam questionar suas crenças, crenças em geral e as crenças sobre ensino. Para Barcelos (2004), isso pode favorecer a formação de sujeitos críticos, reflexivos e questionadores do mundo a sua volta. 3) Necessidade de professores estarem preparados para lidar com a diversidade das crenças em suas salas de aula, pois cada sujeito carrega dentro de si crenças que foram construídas a partir de experiências pessoais e sociais. Essa última implicação se coloca como um desafio para os professores que precisam encontrar estratégias para lidar com eventuais conflitos entre as crenças existentes em sala de aula.

\section{METODOLOGIA DA PESQUISA}

Esta pesquisa se caracteriza como uma abordagem quali-quantitativa, de natureza descritiva e interpretativista (SCHNEIDER; et al, 2017). A fim de fazer uma análise quantitativa e qualitativa da produção acadêmica e científica acerca das crenças, concentramos nossa coleta de dados no catálogo de teses e dissertações da CAPES (Coordenação de Aperfeiçoamento de Pessoal de Nível Superior), onde são armazenados os trabalhos de conclusão dos cursos de pós-graduação stricto sensu das universidades do país. A produção acadêmica que procuramos mapear e discutir engloba dissertações de programas de pós-graduação de universidade brasileiras, que podem ser públicas ou privadas. Objetivamos investigar as pesquisas em crenças concentrando nossa atenção aos estudos realizados no campo de da Linguística Aplicada, especificamente nas perspectivas relacionadas ao ensino. 


\section{$=$ TRAMA $=$}

O acesso a essa produção foi feito através da busca no painel de informações quantitativas da CAPES. A princípio, para que fosse feito o levantamento de dissertações sobre a pesquisa em crenças desde a década de 1990 até o ano de 2018. Nesse aspecto, a pesquisa assume um caráter quantitativo, pois apresenta um panorama das dissertações produzidas mostrando, com números significativos, a evolução, ampliação e importância das pesquisas em crenças no Brasil. A utilização do catálogo de teses e dissertações cria, conforme Ferreira (2002), condições para que o pesquisador estabeleça um primeiro contato com o tema de seu interesse, fazendo um mapeamento do que já foi construído e uma articulação entre a produção construída ou que pretende construir.

A partir do levantamento feito, encontramos 146 dissertações produzidas de 1990 até 2018 para a constituição do nosso corpus. Selecionamos 10 dissertações produzidas em 2018 para analisarmos os seguintes aspectos: os programas aos quais pertencem essas dissertações, o título e os resumos. Na análise, procuramos saber quais os programas que mais produziram trabalhos baseados nas teorias das crenças e identificar nos títulos os temas mais recorrentes e o viés teórico da pesquisa, considerando o nosso interesse na perspectiva das crenças relacionadas ao ensino de línguas. Nos resumos, sublinhamos os objetivos e a metodologia utilizada, bem como os resultados alcançados. Nesse sentido, nossa pesquisa possui também um caráter qualitativo, haja vista envolver uma análise interpretativista detalhada acerca do objeto de nosso estudo. A pesquisa é compreendida também como descritiva, pois ao investigar as pesquisas em crenças sobre o ensino-aprendizagem de línguas, observa, registra e descreve as características desse fenômeno, relacionando e analisando aspectos a ela pertinentes. É qualitativa e interpretativista no sentido de buscar a inferência das crenças, levando em conta a natureza e a complexidade do mundo social que permite ao pesquisador a construção de significados por meio dos quais ele mesmo percebe a realidade.

\section{PESQUISAS SOBRE CRENÇAS NO BRASIL}

O acesso à produção acadêmica e científica relacionada ao estudo das crenças sobre o ensino-aprendizagem de línguas permite uma visão panorâmica da evolução das pesquisas feitas no Brasil. O interesse crescente dos pesquisadores pelas crenças como objeto de estudo coloca em evidência a importância desse tema. Barcelos (2004) afirma que o início dessas pesquisas no Brasil ocorreu na segunda metade da década de 90 , no campo de conhecimentos da Linguística Aplicada. E desde então, de maneira específica, mostra-se em estreita relação com os diferentes paradigmas de ensino de línguas. Seu surgimento também está associado a dois importantes eventos: o Congresso da ALAB (Associação de Linguística Aplicada do Brasil) em 1997 e a Conferência da Associação Internacional de Linguística Aplicada em 1999. Nas últimas décadas, esse tema está presente nos espaços de importantes centros acadêmicos do país, especialmente nos programas de pós-graduação.

Para mostrar a evolução e importância das pesquisas em crenças no Brasil, fizemos a coleta de dados no catálogo de teses e dissertações da CAPES (Coordenação de Aperfeiçoamento de Pessoal de Nível Superior), com o intuito de fazermos uma relação das dissertações que tratam da pesquisa em crenças, desde a década de 1990 até o ano de 2018, nos programas de pós-graduação de universidades brasileiras, públicas ou privadas. O recorte histórico se justifica pelo fato de ter sido a partir dos anos 90 que o interesse pelos estudos de crenças no processo de ensino-aprendizagem surgiu no Brasil. Ao filtrarmos as dissertações produzidas, encontramos 146 voltadas para a área de ensino de línguas e percebemos uma evolução significativa dessas pesquisas nos cursos de pós-graduação do país no decorrer das últimas décadas. O gráfico, a seguir, sintetiza essa informação. 


\section{$=\mathrm{T} R A M A=$}

GRÁFICO 1: Dissertações produzidas

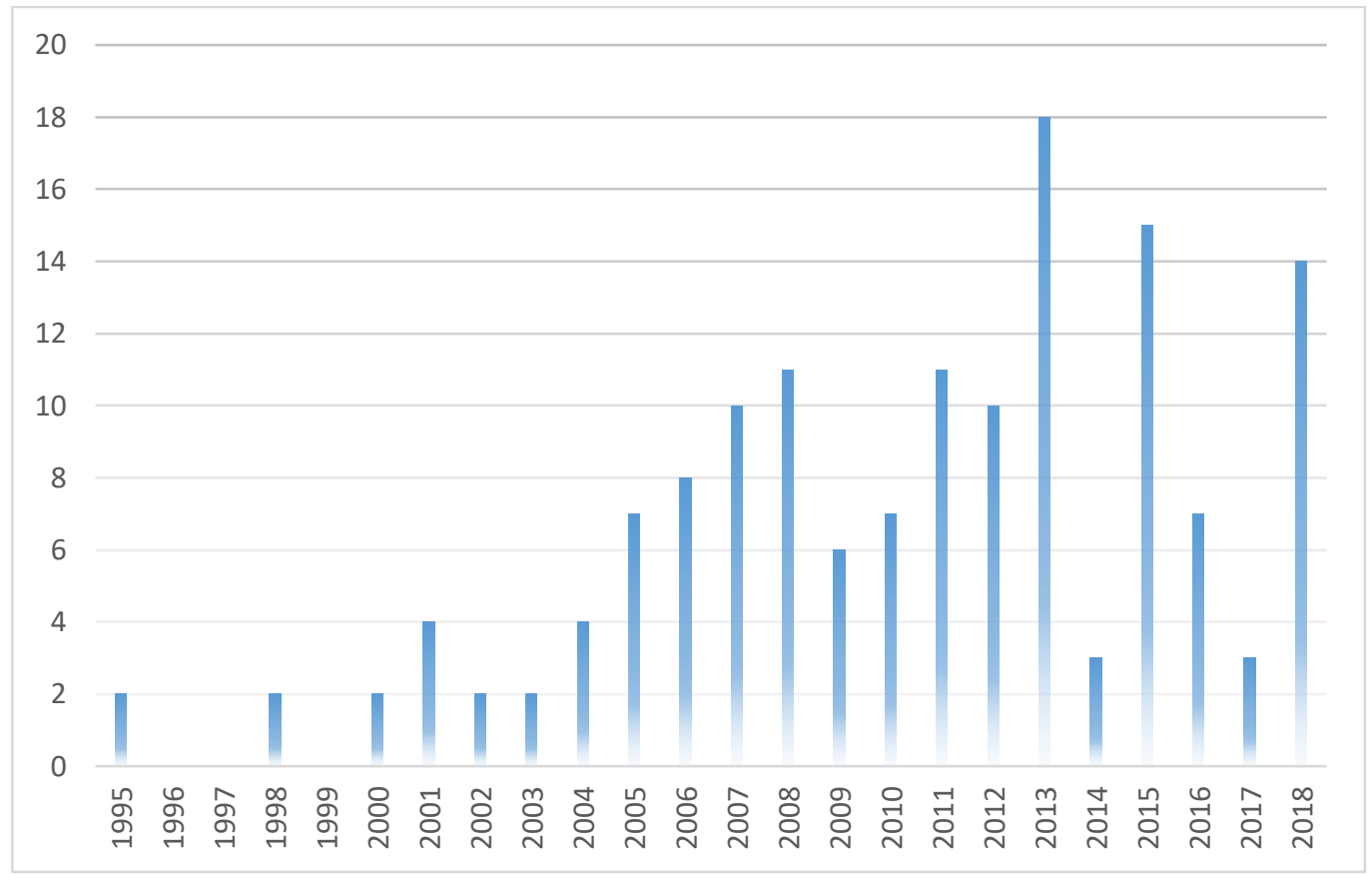

De acordo com o gráfico 1, é possível observar um crescente interesse pelas pesquisas em crenças no Brasil, principalmente entre os anos de 2004 a 2013, uma quantidade significativa de dissertações produzidas sobre crenças no processo ensino-aprendizagem apresenta-se de maneira considerável, o que só reafirma a relevância dessa temática nas discussões, reflexões e aprimoramento do ensino de línguas no Brasil. O levantamento das pesquisas realizadas no âmbito das crenças no processo ensino-aprendizagem em línguas revelou que os programas de pós-graduação, em diferentes universidades do Brasil, têm se interessado pela temática e têm investido estudos, visando contribuir com melhorias no exercício de ensinar e aprender línguas nas escolas brasileiras.

Considerando que o propósito deste trabalho é apresentar apenas uma visão panorâmica, é importante deixar claro que esses dados não informam a quantidade exata de dissertações produzidas. Selecionamos 146 dissertações de programas de mestrado de 43 universidades brasileiras (públicas e privadas). Em 33 universidades, encontramos uma quantidade de dissertações que varia de 1 a 3. A quantidade encontrada nas outras dez varia de 4 a 35 dissertações. À título de ilustração, apresentamos um gráfico com uma amostra das universidades que mais realizaram pesquisas em crenças e seus programas de pós-graduação. 
GRÁFICO 2: Pesquisas em crenças

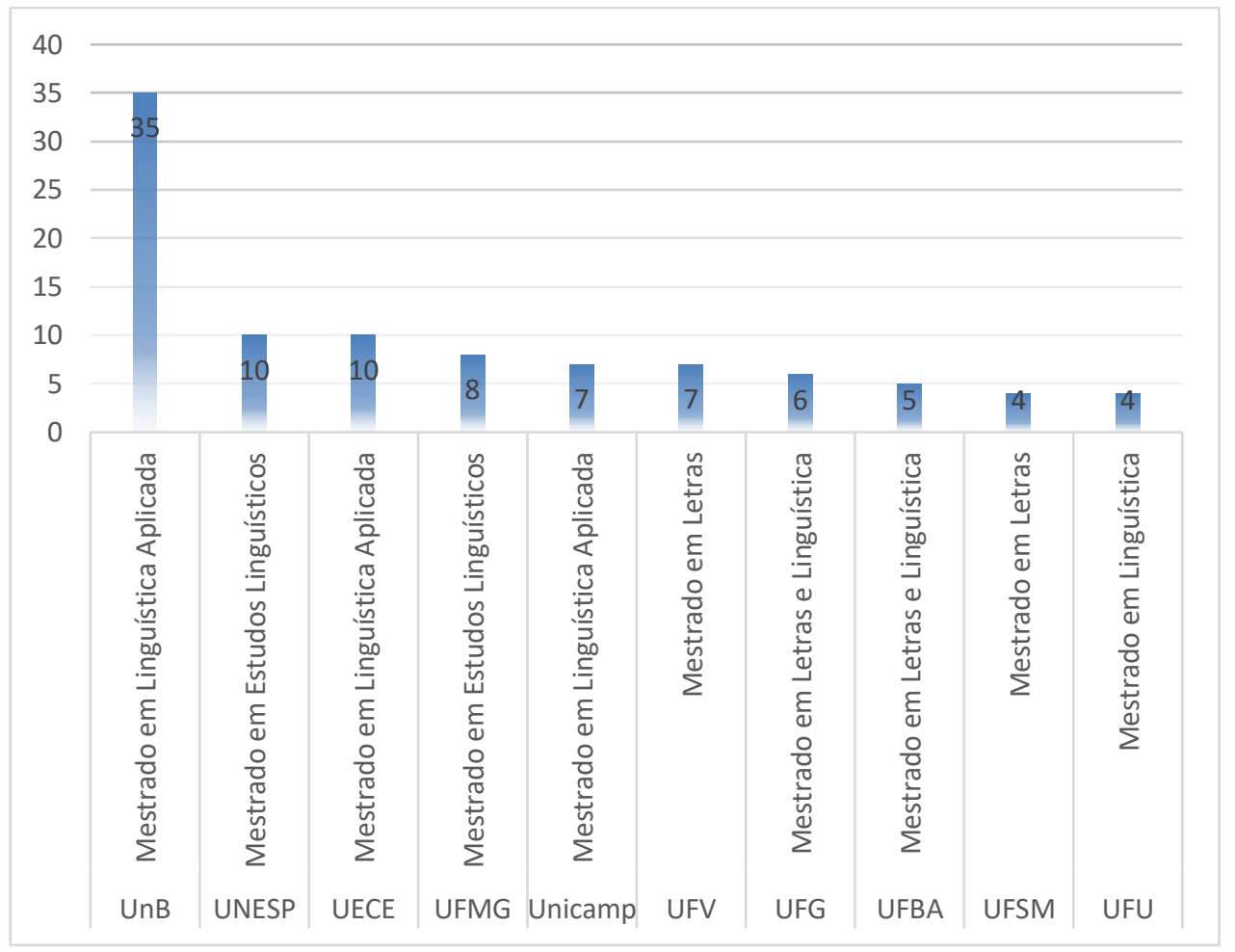

Com o intuito de possibilitar uma visão geral do que vem sendo produzido na área, organizamos os dados de modo a mostrar os programas que mais produziram dissertações, para, em seguida, falarmos sobre o foco e as principais características das pesquisas.

GRÁFICO 3: Soma de pesquisas por programas

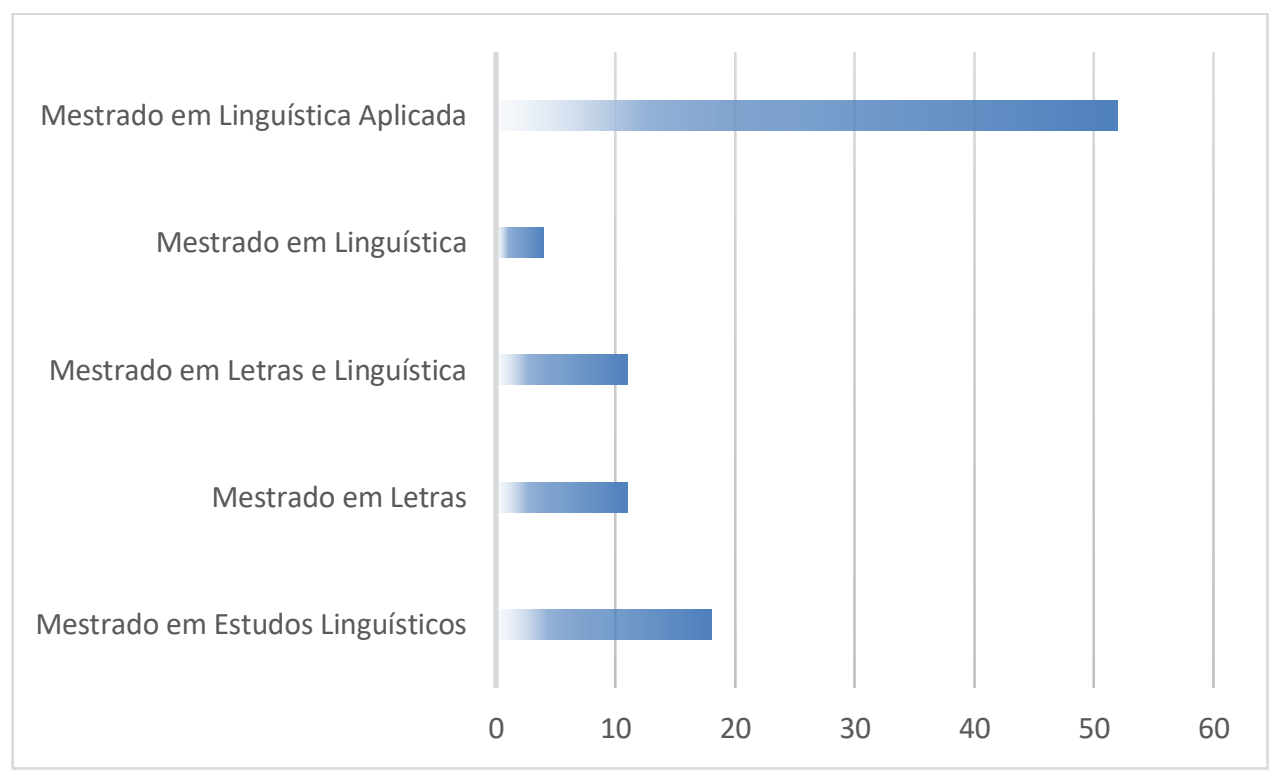




\section{$=$ TRAMA $=$}

Podemos perceber como se acham as principais tendências no tratamento das pesquisas em crenças no Brasil, com base na análise dos títulos das dissertações.

- Mestrado em Linguística Aplicada (UnB, UECE, Unicamp) - foco nas crenças em relação ao ensino-aprendizagem de língua estrangeira: escrita, tradução, gramática, gêneros textuais, textos literários; o papel do professor, a formação profissional, a prática pedagógica; a identidade dos alunos; o ensino à distância.

- Mestrado em Estudos Linguísticos (UNESP, UFMG) - foco nas crenças em relação ao ensino-aprendizagem de língua estrangeira: autonomia e motivação, abordagem de ensino, o papel do aprendiz, a escola pública, a cultura de falantes nativos, a formação reflexiva, prática de avaliação, processo interativo.

- Mestrado em Letras e Linguística (UFG, UFBA) - foco nas crenças em relação ao ensino-aprendizagem de língua estrangeira: correção de erros, leitura, o uso da música, avaliação oral, ensino-aprendizagem para surdos, alunos da zona rural.

- Mestrado em Letras (UFV, UFSM) - foco nas crenças em relação ao ensinoaprendizagem de língua estrangeira: motivação e competência de professores, aprendizagem da escrita, processo de construção da identidade, tecnologias digitais da informação e comunicação, motivação e identidade, ensino instrumental, avaliação da aprendizagem.

Para maior aprofundamento de nosso estudo e análise qualitativa dos dados, incluímos as dissertações produzidas no ano de 2018 sobre crenças no processo de ensinoaprendizagem de línguas, excluindo as demais que, embora abordassem o fenômeno crenças, não enfatizavam o ensino-aprendizagem de línguas. Os dados inseridos no Catálogo de teses e dissertações da CAPES nos direciona, por meio de um link, à Plataforma Sucupira onde é possível o acesso às dissertações com as seguintes informações: Instituição de Ensino Superior, Programa, Título, Autor, Tipo de Trabalho de Conclusão, Data Defesa, Resumo etc.

Através da leitura e análise dos resumos, foram analisados os seguintes aspectos: objetivo da pesquisa, metodologia utilizada, sujeitos da pesquisa e resultados alcançados. Notamos através de nossa investigação que em 2018 muitos trabalhos acerca de crenças no processo de ensino-aprendizagem de línguas foram produzidos em diferentes universidades do país. Dos estudos encontrados, verificamos que a maioria deles tiveram interesse em investigar as crenças dos professores (SILVA, 2018; HAUS, 2018; LIMA, 2018; SPITZ, 2018; MACHADO, 2018; NUNES 2018; MONTE, 2018; SANTOS G., 2018) e outros poucos trabalhos abordam crenças de alunos (SANTOS, S., 2018; PALMER, 2018). Procuramos fazer uma análise descritiva de cada uma delas, mapeando os dados gerais: objetivos, metodologia e resultados.

Silva (2018), ao pesquisar sobre as crenças constitutivas de uma professora em relação ao ensino e à aprendizagem, por meio do uso da música como recurso didático-pedagógico nas aulas de Língua Inglesa, pretendeu investigar se as crenças da professora e as músicas em inglês eram mobilizadas na prática docente pela perspectiva reflexiva e crítica, sob o ponto de vista de pesquisadores da área. Para tanto, fez uso da metodologia do tipo estudo de caso, com abordagem qualitativa-interpretativista. Como instrumento de coleta e análise dos dados, a pesquisadora fez uso de entrevista semiestruturada, um questionário aberto e as observações de aulas em que foi aplicado o projeto. A análise dos dados possibilitou à pesquisadora concluir que há uma perspectiva reflexiva e crítica nas crenças da professora e isso é notado em sua prática. A pesquisa também revelou que a professora acredita que a música nas aulas de língua inglesa (LI) funciona como uma ferramenta didático-pedagógica, auxiliando o aluno a entender, 


\section{$=$ TRAMA $=$}

com mais facilidade, os conteúdos linguísticos de uma língua estrangeira, dando a ele possibilidade de adquirir conhecimentos socioculturais, por meio da contextualização de uma determinada música ao ser mobilizada em sala de aula.

Ao investigar o ensino de pronúncia sob a perspectiva do inglês como língua franca, Haus (2018) concentrou sua pesquisa nas crenças e práticas de professores de língua inglesa do Centro de Línguas e Interculturalidade (CELIN) da Universidade Federal do Paraná (UFPR). O objetivo geral de sua pesquisa foi identificar as crenças e práticas de dois professores de inglês a respeito da pronúncia, bem como de que forma este conjunto se relaciona com Inglês como Língua Franca (ILF). De acordo com a pesquisadora, no cenário de ILF, o ensino de pronúncia se torna mais complexo ao considerarmos questões como modelo de falante nativo, inteligibilidade e a heterogeneidade das situações comunicativas. Para alcançar o objetivo de sua pesquisa, foi realizada uma pesquisa qualitativa de cunho etnográfico. Como instrumento de pesquisa, Haus (2018) aplicou um questionário inicial para uma equipe docente de língua inglesa do CELIN. A partir das informações coletadas através dos questionários, dois participantes foram selecionados para participar das demais etapas da pesquisa. Durante um semestre, os participantes responderam a quatro entrevistas e as aulas de uma turma de cada um foram observadas. Os dados foram categorizados e analisados qualitativamente. Os resultados obtidos através dos diferentes instrumentos de pesquisa possibilitaram um olhar a respeito das abordagens e crenças de cada professor no ensino de pronúncia, bem como o entendimento da importância de um trabalho de formação inicial e/ou continuada na instituição que possibilite leituras, discussões e construções de sentido sob a luz do ILF.

Lima (2018) optou por investigar a formação leitora e literária de uma graduanda do curso de Letras/Espanhol da Universidade Estadual do Ceará, que também é professora do ensino básico. A pesquisa da referida autora considerou a relação entre crenças, formação e prática da professora investigada. Tinha como objetivo investigar uma possível transformação no sistema de crenças da graduanda do curso de Letras/Espanhol da Universidade Estadual do Ceará, sobre sua formação leitora e literária para realizar práticas de leitura literária em aulas de ELE (Espanhol como Língua Estrangeira) no ensino básico. Como instrumento de coleta e análise de dados, foi utilizado um questionário com o intuito de saber as crenças iniciais; um minicurso sobre a formação leitora e literária; a partir desse minicurso, a professora elaborou e aplicou atividades com foco em leitura literária com seus alunos de educação básica. Em seguida, foi aplicado um questionário para saber as crenças finais após o minicurso e experiência em sala de aula. Os resultados demonstraram que os futuros professores de ELE ainda possuem muitas crenças sobre o uso do texto literário em língua espanhola nas aulas de espanhol do ensino básico, porém a pesquisadora comprovou, a partir de seu estudo, que as crenças identificadas não são impossíveis de serem reformuladas, haja vista as mudanças significativas nas crenças da professora em formação após sua experiência com o texto literário. Demonstraram também que as práticas de leitura literária com o texto literário na educação básica tiveram efeitos positivos para a professora e para seus alunos.

Spitz (2018) fez uma investigação sobre as crenças no ensino-aprendizagem de PLH (Português como Língua de Herança). Nessa pesquisa, a autora problematiza os entendimentos emergentes dos professores sobre a "aula de PLH" a partir dos múltiplos espaços que ela pode ocupar. A investigação se caracterizou como uma pesquisa qualitativa, de caráter interpretativista para, a partir do entendimento de que a língua emerge na socialização e na negociação de sentidos e da visão sociocultural de linguagem, problematizar o Sistema de Crenças dos professores e demais envolvidos sobre as "aulas de PLH". Como instrumento de coleta e análise de dados, a pesquisadora apropriou-se de questionários online, entrevista 


\section{$=$ TRAMA $=$}

gravadas em áudio, observação direta e notas de campo. Os resultados obtidos sugeriram que os professores não consideram atividades lúdicas que desenvolvem como aula, o ensino sistemático da língua, embora apontado como um fim nos objetivos, não aparece nas atividades pedagógicas. Os achados da pesquisa também indicaram uma representação estereotipada do aluno e há influência do sistema de crenças na maneira como o professor constrói seu lugar e o lugar do aprendiz de PLH.

As "crenças e ações de uma professora não licenciada" são um tema de uma pesquisa desenvolvida por Machado (2018). Seu interesse foi tratar as crenças sobre ensinoaprendizagem de línguas, numa perspectiva contextual (BARCELOS, 2001). A pesquisa investigou as crenças de uma professora a respeito de como se ensina e se aprende inglês, assim como suas crenças sobre si, na condição de não licenciada e sobre que tipo de profissional pode ensinar inglês. A pesquisa também procurou compreender as relações entre as crenças da participante da pesquisa e suas ações no âmbito profissional, tendo como referência suas experiências de aprendizagem de inglês vivenciadas anteriormente; suas experiências no campo formativo e suas experiências em contexto de atuação profissional. A pesquisa de base qualitativa se configurou como um estudo de caso. Para tanto, utilizou-se como instrumentos de pesquisa: questionário, observação e notas de campo, narrativas escritas e entrevistas. Os achados da investigação revelaram que embora os fatores contextuais do trabalho da professora tenham exercido influência sobre certas práticas e, até mesmo, sobre certas crenças, as crenças decorrentes das experiências de aprendizagem, se comparadas àquelas decorrentes dos outros campos de experiências, mostraram-se mais determinantes nas ações da professora.

Nunes (2018) investigou as crenças e ações de uma professora de língua inglesa sobre a autonomia na aprendizagem de línguas. Com o intuito de fazer uma relação entre crenças e ações da professora participante, a pesquisadora pretendeu, a partir de sua investigação, identificar consonâncias e divergências envolvidas nessa dinâmica. A pesquisa configurou-se como um estudo de caso, de natureza qualitativa e interpretativista. Os instrumentos utilizados para a coleta dos dados resumiram-se em: observações de aulas com notas de campo, entrevistas semiestruturadas e narrativas escritas. Os achados da pesquisa sugeriram que tanto as crenças influenciam as ações da professora quanto as ações e reflexões influenciam para a criação e/ou ressignificação de crenças já existentes. Os dados também revelaram que, embora a participante acreditasse não agir diretamente para desenvolver a autonomia em seus alunos durante suas aulas, suas ações demonstraram diversos momentos favoráveis à aprendizagem autônoma.

Objetivando investigar as crenças e experiências de professores, em relação às tecnologias digitais no ensino de língua portuguesa, Monte (2018) usou como método a pesquisa qualitativa, de caráter descritivo e ainda uma pesquisa colaborativa. Utilizou-se como instrumentos: questionários com questões abertas, os quais foram aplicados a três professores de língua portuguesa do Ensino Fundamental e Médio de escolas públicas municipais; observações em sala de aula, com notas de campo; um momento interventivo com professores e alunos; e uma entrevista. A mensuração dos dados revelou que os professores acreditam que as tecnologias são ferramentas relevantes para a aprendizagem dos alunos, porém ainda prevalece um desafio para lidar com esses recursos. Ao analisar as crenças e as experiências dos professores, a pesquisadora identificou que a dificuldade do trabalho com as tecnologias não é a ausência delas na escola, mas a falta de formação que capacite os professores a fazerem uso das ferramentas tecnológicas de forma pedagógica e educativa. 


\section{$=$ TRAMA $=$}

Santos G. (2018) também investigou as crenças de professores de línguas a respeito da inserção das tecnologias digitais da informação e comunicação em suas práticas. A pesquisa qualitativa, de cunho etnográfico, contou com a elaboração e aplicação de questionário e entrevista semiestruturada, realizada com três professores de línguas atuantes no ensino fundamental de uma escola pública do agreste pernambucano. Dos três professores que passaram pelas primeiras etapas da investigação, foi escolhido um deles para observar sua prática em sala de aula durante um bimestre. Ao analisar os dados coletados, identificou-se que, segundo as crenças dos professores, as tecnologias digitais contribuem para a dinamização do processo de ensino-aprendizagem de línguas, são imprescindíveis nas práticas pedagógicas dos professores e proporcionam aos conteúdos mais dinamismo e acessibilidade. No entanto, durante a observação das aulas do professor selecionado, percebeu-se que, apesar de apresentar em seu discurso crenças de que as tecnologias digitais poderiam contribuir para o ensino de línguas, suas práticas não correspondiam as suas crenças, haja vista que suas ações eram conservadoras e desprezava o potencial das linguagens online e dos textos multimodais presentes em tais tecnologias e que podem potencializar o processo de ensino-aprendizagem de línguas.

Percebemos, a partir da descrição dos trabalhos mencionados, que existem muitas investigações que tratam das crenças, tendo como colaboradores de pesquisa os professores. Santos S. (2018) procurou desenvolver seu estudo sobre crenças no processo de ensinoaprendizagem de espanhol, tendo como participantes de sua pesquisa os alunos. O intuito da autora foi investigar, identificar e comparar as crenças de alunos de espanhol de duas escolas da região metropolitana de Belo Horizonte. Para tanto, apoiou-se na metodologia qualitativa e utilizou dois questionários abertos sobre crenças, uma narrativa visual e uma entrevista. Os resultados apontaram que os alunos acreditam que o espanhol é mais fácil de aprender em relação a outras línguas. Além disso, os resultados também sugeriram que as crenças apresentaram relação com fatores contextuais como idade, classe social e objetivos dos alunos.

Outra dissertação desenvolvida, nesse último ano, e que teve como participantes de pesquisa os alunos, foi a de Palmer (2018). O referido autor decidiu investigar sobre crenças, identidades e classe social de aprendizes da língua inglesa, fazendo uma comparação entre os sujeitos aprendizes dos Estados Unidos e o Brasil. O objetivo de seu estudo foi identificar e comparar as identidades, crenças e fatores de classe social de dois grupos de participantes em dois contextos: alunos imigrantes nos Estados Unidos e alunos brasileiros, ambos em seu primeiro ano do ensino médio em escola pública de bairros de classe social-econômica baixa. Para atender ao objetivo de sua pesquisa, Palmer (2018) utilizou alguns instrumentos de coleta de dados: primeiro foi aplicado um questionário a doze alunos de língua inglesa pertencentes a contextos parecidos; uma entrevista; narrativas escritas e visuais. A mensuração dos dados revela a língua inglesa expressa como forma de capital e uma relação recorrente entre crenças, identidades e classe social. O inglês considerado como capital tem afetado as crenças pessoais e sociais sobre aprendizagem de inglês, o que consequentemente atinge a identidade dos participantes como futuros usuários de inglês. Percebeu-se que os alunos imigrantes dos Estados Unidos fazem esforço para pertencer ao grupo falantes do inglês de sua comunidade, e os alunos brasileiros tentam ou aderir as crenças de sua comunidade onde o inglês é inacessivel a seus habitantes ou romper com essa crença, investindo na aprendizagem da referida língua estrangeira. Palmer conclui seu estudo afirmando que sua investigação traz implicações para a aprendizagem de inglês e apresenta impactos sociais para o ensinoaprendizagem de língua inglesa. 


\section{$=$ TRAMA $=$}

Analisando o conteúdo dessas dissertações produzidas no ano 2018, vimos que os temas mais recorrentes foram: crenças de professores sobre ensino aprendizagem; práticas pedagógicas; estratégias de aprendizagem utilizadas pelos professores; crenças sobre o uso educativo das tecnologias digitais; bem como as crenças dos alunos sobre aprendizagem de línguas estrangeiras. No que se refere às metodologias empregadas para coleta e análise dos dados, pudemos observar que todas as dissertações utilizam a abordagem qualitativa. Sobre o método, percebemos pesquisas do tipo estudo de caso, pesquisa narrativa e pesquisa descritiva e explicativa. Quanto aos instrumentos para coleta e análise de dados, os trabalhos utilizaram questionários e entrevistas semiestruturadas. Partindo dessas averiguações, podemos refletir que as pesquisas realizadas no âmbito das crenças no processo de ensinoaprendizagem requerem métodos e instrumentos adequados às pesquisas em crenças, as quais demandam uma postura ética, reflexiva e responsável por parte do pesquisador, já que se trata de investigar concepções e ações dos sujeitos que pensam, (re)constroem-se e agem a partir de experiências e interações com o outro e com o meio do qual fazem parte.

\section{CONSIDERAÇÕES FINAIS}

As pesquisas em crenças sobre o ensino-aprendizagem de línguas vêm conquistando um espaço cada vez maior. A apresentação do panorama das dissertações produzidas no Brasil aponta para esse fato importante. Nossa investigação permitiu o levantamento de 146 dissertações produzidas de 1990 até 2018, o que mostra um crescente interesse pelas pesquisas em crenças. Durante esse percurso histórico, o conceito de crenças ganha contornos cada vez mais definidos, enquanto se tem buscado explicitar sua relação com o processo ensino-aprendizagem. É válido ressaltar que as implicações das crenças discutidas se apresentam como um desafio para professoras e professores, sendo necessário refletir para poder promover mudanças de crenças e atitudes diante das práticas pedagógicas cotidianas. As crenças de professores e alunos devem ser enxergadas como possibilidades para que formadores e aprendizes possam evoluir de forma, construtiva, intelectual e também humana. O interesse pelas pesquisas nos cursos de pós-graduação no Brasil nos permite considerar a relevância que as crenças têm assumido no processo de ensinar e de aprender. Os trabalhos de pós-graduação, analisados no ano de 2018, apontam que as crenças de professores e alunos interferem diretamente em suas ações em sala de aula, e que refletir sobre elas pode favorecer mudanças relacionadas às práticas educacionais, e, consequentemente, melhorias do processo de ensino-aprendizagem das escolas. Com base nas reflexões dos autores mencionados, neste trabalho, e nos resultados obtidos a partir dos dados coletados em nosso estudo, reconhecemos que as crenças são determinantes para o agir humano e, por assim ser, não se pode pensar e fazer educação sem considerá-las. É preciso, contudo, continuar investigando, refletindo e (re)construindo a si e ao fazer docente.

\section{REFERÊNCIAS}

AVILA, A. P.; MARCHESAN, M. T. N. Crenças sobre avaliação da aprendizagem: o dizer de uma professora de espanhol de escola pública. Doutorado em LETRAS Instituição de Ensino: Universidade Federal de Santa Maria. Santa Maria - RS, 2018.

BARCELOS, A. M. F. Metodologia de pesquisa das crenças sobre aprendizagem de línguas: estado da arte. Revista Brasileira de Linguística Aplicada, v. 1, n. 1, p. 71-92, 2001. Crenças sobre aprendizagem de língua, Linguística Aplicada e ensino de línguas. Linguagem \& Ensino, vol. 7, n 1, p. 123-156, 2004. Reflexões acerca de mudanças de crenças sobre ensino e aprendizagem de línguas. Revista

Brasileira de Linguística Aplicada, v. 7, n. 2, p. 109-138, 2007.

BOMFIM, B. B. S. B.; CONCEIÇÃO M. P. Crenças de aprendizagem de línguas e a formação reflexiva do professor. Revista Horizontes de Linguística Aplicada, v. 8, n. 1, p. 54-67, 2009. 
HAUS, C. Ensino de pronúncia sob a perspectiva do inglês como língua franca: crenças e práticas de professores de inglês do CELIN - UFPR'. 2018. 172 f. Dissertação (Mestrado em Letras). Instituição de Ensino: Universidade Federal do Paraná, Curitiba, 2018.

LIMA, M. A. M. de. Formação leitora e literária de graduando(a)s de letras/espanhol da UECE: um estudo sobre a relação crenças- formação-prática de uma professora de espanhol'. 2018. 184 f. Dissertação (Mestrado em Linguística Aplicada). Instituição de Ensino: Universidade Estadual do Ceará, Fortaleza - CE, 2018.

MACHADO, A. S. Crenças, experiências e ações de uma professora de inglês não licenciada: um estudo de caso '. 2018. 164 f. Dissertação (Mestrado em Linguística Aplicada). Instituição de Ensino: Universidade de Brasília, Brasília, 2018.

MONTE, H. S. Crenças e experiências de professores sobre as tecnologias digitais no ensino de Língua Portuguesa. 2018. 121 f. Dissertação (Mestrado em Ensino Instituição de Ensino). Universidade do Estado do Rio Grande do Norte, Pau dos Ferros - RN, 2018.

NUNES, D. A. A construção da autonomia na sala de aula de línguas: uma análise das crenças, ações e reflexões de uma professora de inglês (LE). 2018. 162 f. Dissertação (Mestrado em Linguística Aplicada). Instituição de Ensino: Universidade de Brasília, Brasília, 2018.

PALMER, M. M. Beliefs, identities and social class of English language learners - a comparative study between the United States and Brazil' 2018. 100 f. Dissertação (Mestrado em LETRAS). Instituição de Ensino: Universidade Federal de Viçosa, Viçosa-MG, 2018.

SANTOS, G. F. Crenças de professores(as) de línguas a respeito da inserção das tecnologias digitais da informação e comunicação (TDIC) em suas práticas'. 2018. 138 f. Dissertação (Mestrado em Educação Contemporânea). Instituição de Ensino: Universidade Federal de Pernambuco, Pernambuco, 2018.

SANTOS, L. I, S. Crenças e ensino de línguas - uma entrevista com Ana Maria Ferreira Barcelos. Revista de Letras Norte@mentos. Estudos Linguísticos, Sinop, v, 2, n. 4, p. 191-194, 2009.

SANTOS, S. L. C. Crenças de alunos sobre Ensino e aprendizagem de Espanhol'. 2018. 117 f. Dissertação (Mestrado em Letras). Instituição de Ensino: Universidade Federal de Viçosa, Viçosa-MG, 2018.

SCHNEIDER, E. M.; FUJII, R. A. X.; CORAZZA, M. J. Pesquisas quali-quantitativas: contribuições para a pesquisa em ensino de ciências. Revista Pesquisa Qualitativa. São Paulo (SP), v.5, n.9, p. 569-584, dez. 2017.

SILVA, A. R. R. A(s) crença(s) constitutiva(s) de uma professora em relação ao uso da música como recurso didático para o ensino de Língua Estrangeira (Inglês): relação entre crenças contextuais, reflexividade e criticidade'. 2018. 147 f. Dissertação (Mestrado em Letras: Ensino de Língua e Literatura). Instituição de Ensino: Universidade Federal do Tocantins, Araguaína - TO, 2018.

SILVA, K. A. Crenças sobre o ensino aprendizagem de línguas na Linguística Aplicada: um panorama histórico dos estudos realizados no contexto brasileiro. Linguagem \& Ensino, v. 10, n. 1, p. 235-271, 2007.

SPITZ, C. A. Crenças no ensino-aprendizagem do Português como Língua de Herança: problematizações acerca da "aula de PLH" como espaço de letramento, atravessamento e constituição social'. 2018. $145 \mathrm{f}$. Dissertação (Mestrado em Letras). Instituição de Ensino: Universidade do Estado do Rio de Janeiro, Rio de Janeiro, 2018. 